\title{
ERRATUM
}

Paolo Luchini · Flavio Giannetti · Vincenzo Citro

\section{Erratum to: Error sensitivity to refinement: a criterion for optimal grid adaptation}

Published online: 13 April 2017

(C) Springer-Verlag Berlin Heidelberg 2017

Erratum to: Theor. Comput. Fluid Dyn.

DOI 10.1007/s00162-016-0413-x

In the original publication, the second author name has been incorrectly published as Flavio Giannnetti.

The correct name should read as Flavio Giannetti.

This has been corrected in the original version of the article.

The online version of the original article can be found under doi:10.1007/s00162-016-0413-x.

P. Luchini · F. Giannetti · V. Citro ( $\varangle)$

DIIN, University of Salerno, Via Giovanni Paolo II, 84084 Fisciano, SA, Italy

E-mail: vcitro@unisa.it 